\title{
APOE $\& 4$ Allele-associated Alzheimer's disease risk is consistent with increased lifetime exposure to a neurotoxic
} process

\author{
Carr J Smith ${ }^{1 *}$ and J. Wesson Ashford ${ }^{2}$ \\ ${ }^{1}$ Florida State University, Department of Nurse Anesthesia, USA \\ ${ }^{2}$ Stanford University and VA Palo Alto Health Care System, USA
}

\begin{abstract}
In the adult human brain, approximately one trillion synapses are constructed and deconstructed daily as part of normal learning and memory. A growing body of evidence suggests that Alzheimer's disease (AD) is characterized by dysregulated neuroplasticity processes that initially shift the balance toward synaptic loss causing poor episodic memory, while later changes induce synaptic slaughter causing dementia. Inheritance of a single copy of the apolipoprotein E (APOE) $\varepsilon 4$ allele has been shown to increase the risk of $\mathrm{AD}$ by 3-4-fold, with homozygosity associated with a 12-16-fold increase in risk. Further, there is a decrease of risk associated with the APOE $\varepsilon 2$ allele. The pathological consequence of APOE genotype, accounting for the vast majority of AD risk, has led to intense efforts to understand the mechanistic basis of the interplay between APOE status and loss of synapses. Studies conducted across the age spectrum from infancy through senescence have demonstrated that APOE \&4-positive status is associated with increased brain activity and macromolecule turnover in young healthy individuals, with the reverse extant in elderly subjects. The recent demonstration that the brains of APOE $\varepsilon 4$-positive healthy young adults utilize approximately $16 \%$ more of the lipid membrane constituent docosahexaenoic acid (DHA) opens the possibility that part of the increased long-term neurotoxicity might be explained by pharmacokinetics. For example, if the hippocampal neurons of two individuals possess the same susceptibility to either an endogenous or exogenous stress factor, the neurons with the highest turnover of proteins, lipids, and other macromolecules would experience a larger integrated dose of detriment. Small differences in pharmacokinetic effects might be amplified by the extremely long prodromal phase of $\mathrm{AD}$, i.e., average age of presentation for a homozygous $\varepsilon 4$ is about 68 years of age.
\end{abstract}

\section{Introduction}

A central concept in toxicology is the dose-response relationship [1], with toxicity usually increasing with total dose. Dose-response curves can take different shapes including linear, sigmoidal, survival (Gompertz curve), natural logarithmic, parabolic, and even an inverted $\mathrm{u}$-shape in the case of hormesis [2]. Host factors [3] and co-exposures can play an important role in susceptibility to a variety of factors [4]. Many tissues exhibit a redundancy which when exceeded heralds the onset of clinical symptoms [5].

Parkinson's disease (PD) reportedly follows the pattern of a disease process whose symptoms are manifested when the number of surviving neurons decreases below a certain level. The earliest symptoms of motor dysfunction have been consistently estimated to present at around $30 \%$ loss of the dopaminergic neurons in the substantia nigra of the basal ganglia [6]. Similarly, the early symptoms of memory loss associated with Alzheimer's disease (AD) also present after a large number of neurons have already been lost [7]. In contrast with the $30 \%$ neuronal loss of dopamine neurons calculated to be associated with the appearance of PD symptoms, the more diffuse pathology of $\mathrm{AD}$, affecting several types of neurons, cortical regions, and neuronal systems, renders quantitative estimation of $\mathrm{AD}$ loss more difficult, though the factor most closely related pathologically to dementia is synapse loss $[8,9]$.

While the neuropathology of Alzheimer's disease, first described by Alzheimer in 1906 [10] is characterized by the presence of neuritic plaques (composed of $\beta$-amyloid deposits and neurites made of hyperphosphorylated microtubule associated protein-tau, pTAU) [11] and intracellular neurofibrillary tangles (composed of pTAU) [12], these pathological features are no longer considered as causative of dementia or $\mathrm{AD}$ itself. Rather, these pathological hallmarks of $\mathrm{AD}$ are now viewed more appropriately as representing the incidental results or scars of complex processes which lead initially to impaired neuroplastic processes subserving memory and later to synaptic slaughter causing dementia $[13,14]$.

In principle, $\mathrm{AD}$ is a disease of neuroplasticity [15-18]. Several different molecules and molecular processes which are central to neuroplasticity are likely candidates for contributing to the episodic memory impairment characteristic of early $\mathrm{AD}$ and the dementia of later $\mathrm{AD}$ phases, including projections from the brain stem $[19,20]$ by the norepinephrine neurons of the locus coeruleus [21] and serotonergic neurons of the midbrain raphe nuclei [22]. Despite the diversity of candidates there is general agreement that loss of synapses is the closest correlate of the memory impairment and dementia of $\mathrm{AD}$ across the continuum of cognitive dysfunction $[23,24]$.

It is notable that the brain regions most susceptible to $\mathrm{AD}$-associated synaptic loss are regions with normally high rates of synapse turnover,

Correspondence to: Carr J. Smith, Ph.D., DABT, Florida State University, Department of Nurse Anesthesia 4750 Collegiate Drive, Panama City, FL 32405, USA, E-mail: csmith@pc.fsu.edu

Received: June 03, 2017; Accepted: June 27, 2017; Published: June 30, 2017 
both formation and removal, and a high number of synaptic connections per neuron, particularly the hippocampus [25]. The importance of synaptic remodeling, including by exuberant synaptogenesis and synaptolysis during critical periods of brain development [26], for normal adult brain function [27], and in pathological processes [28] has stimulated intense study. This effort has revealed that hundreds of different proteins displaying a series of signaling and structural functions play a role in synapse formation and normal removal [29]. In addition to the complex array of protein interactions, the formation of and remodeling-associated loss of synapses also involves significant turnover of a number of lipid components of the pre- and post-synaptic membrane [30].

\section{Importance of the APOE Genotype}

The APOE genotype accounts for the vast majority of AD risk and $\mathrm{AD}$ pathology [31,32]. There are three common alleles of the APOE gene, i.e., $\mathrm{APOE} \varepsilon 2$, $\mathrm{APOE} \varepsilon 3$, and $\mathrm{APOE} \varepsilon 4$ [33]. In the general US population, the $\varepsilon 4$ allele prevalence is approximately $13 \%$ [34]. In contrast with unaffected individuals in the US, over $50 \%$ of patients with non-familial AD carry the $\varepsilon 4$ allele [18]. Possession of one $\varepsilon 4$ allele increases the risk of developing $\mathrm{AD}$ by 3 to 4 -fold, and possession of two $\varepsilon 4$ alleles increases risk by 15 -fold, as compared with the $\varepsilon 3 / \varepsilon 3$ genotype [35].

This profound difference in $\mathrm{AD}$ risk results from only minor changes in the structure of the APOE molecule. The three isoforms of APOE differ in amino acid sequence at only chain positions 112 and 158: the APOE $\varepsilon 2$ allele has cysteine at both positions; the APOE $\varepsilon 4$ allele has arginine at both positions; and the APOE $\varepsilon 3$ allele has cysteine at position 112 and arginine at 158 [36]. These small changes in amino acid sequence alter the biological activity of the APOE proteins in multiple ways, one of which is increased liver catabolism of the APOE $\varepsilon 4$ lipoprotein as compared with the APOE $\varepsilon 3$ lipoprotein $[37,38]$.

Recently, Yassine, et al. [39] used positron emission tomography to demonstrate increased docosahexaenoic acid (DHA) uptake in several brain regions in APOE $\varepsilon 4$ carriers. In the AD-susceptible entorhinal sub-region, the mean global gray matter DHA incorporation coefficient was $16 \%$ higher among APOE $\varepsilon 4$ carriers $(n=9)$ than among APOE $\varepsilon 3$ and APOE $\varepsilon 2$ carriers $(n=13, p=0.046)$. These results might be especially significant given that DHA is concentrated at synapses, and comprises up to $40 \%$ of the fatty acids in gray matter [40].

\section{Paradoxical increase in brain activity and cognitive per- formance in young healthy APOE $\varepsilon 4$-positive subjects}

The dominant role played by the APOE $\varepsilon 4$ allele in development of $\mathrm{AD}$ [35], has elicited intense interest in the mechanism of APOE $\varepsilon 4$ control of factors related to $\mathrm{AD}$, particularly the amyloid protein precursor, APP [41], how APOE may be involved in neuroplasticity [42], and the role of APOE in controlling molecules related to AD and neuroplasticity [43]. A number of studies have demonstrated that although the APOE $\varepsilon 4$ allele is associated with reduced cognition in many elderly subjects [18] just the opposite has been shown in young subjects possessing the APOE $\varepsilon 4$ allele. APOE $\varepsilon 4$-positive infants display enhanced mental development [44]. In a Finnish study on 1577 children, motor activity and mental vitality increased significantly by APOE genotype in the ascending order of $\varepsilon 2 / 2, \varepsilon 3 / 2, \varepsilon 4 / 2, \varepsilon 3 / 3$, $\varepsilon 4 / 3$, and $\varepsilon 4 / 4$ [45]. A study conducted on 147 school-aged children reported that $\varepsilon 4$-positive children performed better on a visuospatial task than did ع2-positive children [46]. Higher performance on an IQ test was shown for $\varepsilon 4$-positive young females in China [47]. Increased verbal fluency across six decades of age span has been reported for $\varepsilon 4$-positive subjects [48]. As compared with $\varepsilon 3 / \varepsilon 3$ subjects, during a working memory task an $\varepsilon 3 / \varepsilon 4$ group displayed greater brain activation in the medial prefrontal and parietal regions bilaterally, and in the right dorsolateral prefrontal cortex during a working memory task [49] While increased brain activation during a task may be an indication that neural systems are less efficient for information processing [50], such an increase could also represent a larger number of cortical resources and involved synapses available for processing incoming information. In a study in 340 young healthy volunteers, a Swiss group measured better episodic memory in $\varepsilon 4$ subjects as compared with either $\varepsilon 3$ or $\varepsilon 2$ carriers [51]. In summary, a comprehensive but not exhaustive review of the literature demonstrates that the APOE $\varepsilon 4$ allele is associated with increased brain activity and mental performance in healthy, young individuals.

\section{Synaptic toxicity increases with macromolecular turn- over rate}

The increased rate of DHA incorporation into neuronal membranes reported by Yassine et al. [39], and higher brain activity seen in young, healthy APOE $\varepsilon 4$-positive individuals both support a higher rate of turnover in synaptic macromolecules associated with the APOE $\varepsilon 4$ allele, regardless of explanation. Although neurogenesis can occur in the adult hippocampus [52], and increased neurogenesis increases the rate of synapse formation, synaptogenesis and synaptic pruning occur in the absence of neurogenesis. Synapses are extremely small and incredibly dynamic. It has been estimated that the human brain contains 100 billion neurons, of which 10 billion are pyramidal neurons found in the cerebral cortex. Each of these pyramidal neurons can fire approximately 1,000 times per second. There are approximately $10^{15}$ synapses in the brain, i.e., a quadrillion, with the average half-life of a synapse being about 100 days [53]. Synapse turn-over rates in the brain vary widely anywhere from 15 minutes in the hippocampus [54] to many years in the stable primary cortical regions. Rarely appreciated is the necessity of the adult human brain to prune daily approximately the same number of synapses that it forms as a normal part of learning and memory. The number of synapses formed and actively removed is estimated to be one trillion per day. Given the need to remove so many synapses, it is not surprising that the brain would possess a robust system for synaptic remodeling, i.e., an intrinsic homeostatic capacity for synapse creation and non-pathological synaptotoxicity [55-57].

Although oxidative stress might contribute to the disruption of neuroplasticity seen in $\mathrm{AD}$, the purpose of the following discussion is to illustrate the general principle that toxic insults can accumulate sequentially from repeated exposures. Current technology is not able to measure small errors that occur in lipid and protein composition, and three-dimensional architectural defects propagated during the construction and deconstruction of synapses. In contrast, at the larger cellular level where measurements are possible, non-repaired errors in DNA replication are common. The nervous system is vulnerable to DNA damage for a variety of reasons. First, neurons experience relatively high exposure to reactive oxygen species based on their high mitochondrial respiration rates [58]. Second, the limited capacity for adult neurons to proliferate can lead to the accumulation of mutational damage [59]. Third, neurons stay in $\mathrm{G}_{0}$, i.e., the quiescent or resting phase of the cell cycle and therefore employ the relatively error prone method of DNA repair termed non-homologous end joining [60]. Fourth, oxidative DNA damage can block transcription, and neurons are heavily dependent on transcription [61]. Fifth, vulnerable neurons display an exuberant inflammatory response [62]. The larger number of biochemical reactions occurring per unit time in the brains of 
APOE $\varepsilon 4$ individuals as compared with APOE $\varepsilon 3$ individuals would increase the total lifetime exposure to potentially harmful oxidative species. Similarly, given that increased brain activity and biochemical reaction rate are seen in APOE $\varepsilon 4$ positive infants and children, lifetime exposure to either internally generated neurotoxic macromolecules, or exogenous environmental pathogens or toxins would be increased. The remaining question in Alzheimer's disease is exactly how APOE genotype, presumably through mechanisms related to the production or metabolism of APP, leads to disruption of synapse formation, impaired memory, an excess of synaptic pruning and retraction, with induction of hyperphosphorylation of TAU, leading to massive synapse loss and dementia.

\section{The Gompertz law of survival and AD}

The Gompertz survival function represents a fundamental model of the aging process [63-65], and depends on the initial mortality rate and the doubling time of that rate. The Gompertz curve is applicable across the evolutionary spectrum. In the year 2000, the Gompertz survival function accounted for $99.7 \%$ of the variance in mortality rates for those over the age of 30 in the United States. Across that age span, mortality doubled every 8.2 years for men and 7.5 years for women [18].

The Alzheimer's literature is replete with the statement that $\mathrm{AD}$ is not part of normal aging [66]. The incidence of AD doubles approximately every five years in the population over 60. However, Ashford [18] has compared the Gompertz survival function doubling time of 7.5 and 8.2 years with the five-year doubling time for $\mathrm{AD}$ incidence and shown that $\mathrm{AD}$ tracks age more closely than mortality. The normalcy versus pathogenicity of $\mathrm{AD}$ can be viewed from evolutionary and demographic perspectives. In 1900, the average lifespan in the United States was 47.8 years (both sexes combined) [67]. AD was not a common cause of death in 1900. In contrast, given the current expansion of lifespans, approximately one-third of all men and two-thirds of all women in the US will contract $\mathrm{AD}$ prior to death. Only a limited number of other medical conditions approach the ubiquity of distribution displayed by $\mathrm{AD}$ in the elderly population, e.g., cataracts in whites over $80(70 \%)$ [68]. As a point of comparison, acute macular degeneration with neovascular degeneration occurs in only $15 \%$ of white women over age 80 living in the United Kingdom [69].

Until 300,000 years ago, ancestors of modern humans were ubiquitously $\varepsilon 4 / \varepsilon 4$ and then the $\varepsilon 3$ allele mutated from the ancestral $\varepsilon 4$ allele [70]. The $\varepsilon 3$ allele displayed a competitive survival advantage sufficiently robust to result in the current predominance of the $\varepsilon 3 / \varepsilon 3$ genotype which is now found in over $60 \%$ of the US population [18]. Similarly, the $\varepsilon 2$ allele mutated from the $\varepsilon 3$ allele about 200,000 years ago, but this protective allele has remained relatively rare with the homozygous $\varepsilon 2 / \varepsilon 2$ variant less than $1 \%$, and the $\varepsilon 3 / \varepsilon 2$ heterozygote in about $11 \%$ of the population [71].

\section{Conclusion}

If the hippocampal neurons of two individuals possess the same susceptibility to either an endogenous or exogenous stress factor, the neurons with the highest turnover of proteins, lipids, and other macromolecules would experience a larger integrated dose of detriment. Small differences in pharmacokinetic effects might be amplified by the extremely long prodromal phase of $\mathrm{AD}$, i.e., average age of presentation for a homozygous $\varepsilon 4$ is about 68 years of age.

Given the ancestral primacy of the $\varepsilon 4$ allele, and the evolutionary trade-off of superior performance in youth versus additional years beyond historical lifespans, the abnormality of the $\varepsilon 4$ allele is somewhat a matter of perspective. If part of the APOE $\varepsilon 4$-associated neurotoxic susceptibility is based on pharmacokinetic rather than toxicantreceptor interactions on a per mole basis, future therapies that slow down synaptic pruning might carefully consider differential effects based on APOE allele subtype. Current knowledge of potential sources of Alzeimer's patient heterogeneity is lacking. Reducing at least one important source of inter-subject heterogeneity, i.e., apolipoprotein allele frequency, is advisable. Early attempts at shifting the balance away from synaptic pruning might consider enrolling early stage Alzheimer's patients possessing at least one $\varepsilon 4$ allele.

\section{References}

1. Calabrese, EJ (2016) The emergence of the dose-response concept in biology and medicine. International Journal of Molecular Sciences 17: 2034-2048.

2. Calabrese EJ (2004) Hormesis: a revolution in toxicology, risk assessment and medicine. EMBO Rep 5 Spec No: S37-40. [Crossref]

3. Grassman J (1997) Acquired risk factors and susceptibility to environmental toxicants. Environ Toxicol Pharmacol 4: 209-217. [Crossref]

4. Silins I and Hogberg J (2011) Combined toxic exposures and human health: biomarkers of exposure and effect. Int. J. Environ. Res. Public Health 8: 629-647. [Crossref]

5. Grandjean P (1991) Effects on reserve capacity: significance for exposure limits. Sci Total Environ 101: 25-32. [Crossref]

6. Cheng HC, Ulane CM, Burke RE (2010) Clinical progression in Parkinson disease and the neurobiology of axons. Ann Neurol 67: 715-725. [Crossref]

7. Wilson RS, Leurgans SE, Boyle PA, Bennett DA (2011) Cognitive decline in prodromal Alzheimer disease and mild cognitive impairment. Arch Neurol 68: 351-356. [Crossref]

8. DeKosky ST, Scheff SW (1990) Synapse loss in frontal cortex biopsies in Alzheimer's disease: correlation with cognitive severity. Ann Neurol 27: 457-464. [Crossref]

9. Terry RD, Masliah E, Salmon DP, Butters N, DeTeresa R, et al. (1991) Physical basis of cognitive alterations in Alzheimer's disease: synapse loss is the major correlate of cognitive impairment. Ann Neurol 30: 572-580. [Crossref]

10. Jarvik L (1990) Alzheimer's original paper. Am J Psychiatry 147: 127. [Crossref]

11. Hardy J (2009) The amyloid hypothesis for Alzheimer's disease: a critical reappraisal J Neurochem 110: 1129-1134. [Crossref]

12. Goedert M, Spillantini MG, Jakes R, Rutherford D, Crowther RA (1989) Multiple isoforms of human microtubule-associated protein tau: sequences and localization in neurofibrillary tangles of Alzheimer's disease. Neuron 3: 519-526. [Crossref]

13. Ashford JW, Soultanian NS, Zhang SX, Geddes JW (1998) Neuropil threads are collinear with MAP2 immunostaining in neuronal dendrites of Alzheimer brain. $J$ Neuropathol Exp Neurol 57: 972-978. [Crossref]

14. Coleman PD, Yao PJ (2003) Synaptic slaughter in Alzheimer's disease. Neurobiol Aging 24: 1023-1027. [Crossref]

15. Ashford JW and Jarvik L (1985) Alzheimer's disease: does neuron plasticity predispose to axonal neurofibrillary degeneration? N. Engl. J. Med 313: 388-389. [Crossref]

16. Mesulam MM (1999) Neuroplasticity failure in Alzheimer's disease: bridging the gap between plaques and tangles. Neuron 24: 521-529. [Crossref]

17. Arendt T (2001) Disturbance of neuronal plasticity is a critical pathogenetic event in Alzheimer's disease. Int J Dev Neurosci 19: 231-245. [Crossref]

18. Ashford JW (2004) APOE genotype effects on Alzheimer's disease onset and epidemiology. J Mol Neurosci 23: 157-165. [Crossref]

19. Hertz L (1989) Is Alzheimer's disease an anterograde degeneration, originating in the brainstem, and disrupting metabolic and functional interactions between neurons and glial cells? Brain Res Brain Res Rev 14: 335-353. [Crossref]

20. Trillo L, Das D, Hsieh W, Medina B, Moghadam S, et al. (2013) Ascending monoaminergic systems alterations in Alzheimer's disease. Translating basic science into clinical care. Neurosci Biobehav Rev 37: 1363-1379. [Crossref]

21. Bondareff W, Mountjoy CQ, Roth M (1981) Selective loss of neurons of origin of adrenergic projection to cerebral cortex (nucleus locus coeruleus) in senile dementia. Lancet 1: 783-784. [Crossref]

22. Grinberg LT, Rub U, Ferretti RE, Nitrini R, Farfel JM, et al. (2009) The dorsal raphe nucleus shows phospho-tau neurofibrillary changes before the transentorhinal region in Alzheimer's disease. A precocious onset? Neuropathol Appl Neurobiol 35: 406-416. [Crossref] 
23. Scheff SW, Price DA, Schmitt FA, Mufson EJ (2006) Hippocampal synaptic loss in early Alzheimer's disease and mild cognitive impairment. Neurobiol Aging 27: 13721384. [Crossref]

24. Brickman AM, Small SA, Fleisher A (2009) Pinpointing synaptic loss caused by Alzheimer's disease with fMRI. Behav Neurol 21: 93-100. [Crossref]

25. Druckmann S, Feng L, Bokyoung L, Yook C, Zhao T, et al. (2014) Structured synaptic connectivity between hippocampal regions. Neuron 81: 629-640. [Crossref]

26. Colón-Ramos DA (2009) Synapse formation in developing neural circuits. Curr Top Dev Biol 87: 53-79. [Crossref]

27. Gage FH (2004) Structural plasticity of the adult brain. Dialogues Clin Neurosci 6: 135-141. [Crossref]

28. Rizzo V, Arico I, Mastroeni C, Morgante F, Liotta G, et al. (2009) Dopamine agonists restore cortical plasticity in patients with idiopathic restless legs syndrome. Movement Disorders 24: 710-715. [Crossref]

29. Schoch S, Gundelfinger ED (2006) Molecular organization of the presynaptic active zone. Cell Tissue Res 326: 379-391. [Crossref]

30. Rohrbough J, Broadie K (2005) Lipid regulation of the synaptic vesicle cycle. Nat Rev Neurosci 6: 139-150. [Crossref]

31. Roses AD (1996) Apolipoprotein E alleles as risk factors in Alzheimer's disease. Annu Rev Med 47: 387-400. [Crossref]

32. Raber J, Huang Y, Ashford JW (2004) ApoE genotype accounts for the vast majority of AD risk and AD neuropathology. Neurobiology of Aging 25: 641-650. [Crossref]

33. Yassine HN, Braskie MN, Mack WJ, Castor KJ, Fonteh AN, et al. (2017a) Association of docosahexaenoic acid supplementation with Alzheimer disease stage in apolipoprotein E $\varepsilon 4$ carriers - a review. JAMA Neurology 74: 339 - 347. [Crossref]

34. Evans DA, Beckett LA, Field TS, Feng L, Albert MS, et al. (1997) Apolipoprotein E ?4 and incidence of Alzheimer disease in a community population of older persons. JAMA 277: 822-824. [Crossref]

35. Corder EH, Saunders AM, Strittmatter WJ, Schmechel DE, Gaskell PC, et al. (1993) Gene dose of apolipoprotein E type 4 allele and the risk of Alzheimer's disease in late onset families. Science 261: 921-923. [Crossref]

36. Mahley RW, Weisgraber KH, Huang Y (2009) Apolipoprotein E: structure determines function, from atherosclerosis to Alzheimer's disease to AIDS. J Lipid Res. 50(suppl):S183-S188. [Crossref]

37. Weisgraber KH (1990) Apolipoprotein E distribution among human plasma lipoproteins: role of the cysteine-arginine interchange at residue 112. J Lipid Res 31:1503-1511. [Crossref]

38. Polozova A1, Salem N Jr (2007) Role of liver and plasma lipoproteins in selective transport of n-3 fatty acids to tissues: a comparative study of 14C-DHA and 3H-oleic acid tracers. J Mol Neurosci 33: 56-66. [Crossref]

39. Yassine HN, Croteau E, Rawat V, Hibbeln JR, Rapoport SI, et al. (2017b) DHA brain uptake and APOE4 status: a PET study with [1-11C]-DHA. Alzheimer's research \& therapy 9:23-31. [Crossref]

40. La L, Hansen HS, Jørgensen MH, Michaelsen KF (2001) The essentiality of long chain n-3 fatty acids in relation to development and function of the brain and retina. Prog Lipid Res 40:1-94. [Crossref]

41. Ye SM, Huang YD, Mullendorff K, Dong LM, Giedt G, et al. (2005) Apoliprotein (apo) E4 enhances amyloid beta peptide production in cultured neuronal cells: ApoE structure as a potential therapeutic target. PNAS 102: 18700-18705. [Crossref]

42. Teter B, Ashford JW (2002) Neuroplasticity in Alzheimer's disease. J Neurosci Res 70: 402-437. [Crossref]

43. Huang YA, Zhou B, Wernig M, Südhof TC (2017) ApoE2, ApoE3, and ApoE4 Differentially Stimulate APP Transcription and A $\beta$ Secretion. Cell 168: 427-441. [Crossref]

44. Wright RO, Hu H, Silverman EK, Tsaih SW, Schwartz J, et al. (2003) Apoliprotein E genotype predicts 24-month Bayley scales infant development scores. Pediatr Res 54 819-825. [Crossref]

45. Keltikangas-Järvinen L, Räikkönen K, Lehtimäki T (1993) Dependence between apolipoprotein E phenotypes and temperament in children, adolescents, and young adults. Psychosom Med 55: 155-163. [Crossref]

46. Bloss CS, Delis DC, Salmon DP, Bondi MW (2010) APOE genotype is associated with lefthandedness and visuospatial skills in children. Neurobiol. Aging 31: 787-795. [Crossref]

47. Yu YW-Y, Lin C-H, Chen S-P, Hong C-J, Tsai S-J (2000) Intelligence and event-related potentials for young female human volunteer apolipoprotein $\mathrm{E} \varepsilon 4$ and non- $\varepsilon 4$ carriers. Neuroscience Letters 294: 179-181. [Crossref]
48. Alexander DM, Williams LM, Gatt JM, Dobson-Stone C, Kuan SA, et al. (2007) The contribution of apoliprotein $\mathrm{E}$ alleles on cognitive performance and dynamic neural activity over six decades. Biological Psychology 75: 229-238. [Crossref]

49. Wishart HA, Saykin AJ, Rabin LA, Santulli RB, Flashman LA, et al. (2006) Increased brain activation during working memory in cognitively intact adults with the APOE epsilon4 allele. Am J Psychiatry 163: 1603-1610. [Crossref]

50. Parks RW, Crockett DJ, Tuokko H, Beattie BL, Ashford JW, et al. (1989) Neuropsychological "systems efficiency" and positron emission tomography. $J$ Neuropsychiatry Clin Neurosci 1: 269-282. [Crossref]

51. Mondadori CR, de Quervain DJ, Buchmann A, Mustovic H, Wollmer MA, et al. (2007) Better memory and neural efficiency in young apolipoprotein E epsilon4 carriers. Cereb Cortex 17: 1934-1947. [Crossref]

52. Kempermann G, Song H, Gage FH (2015) Neurogenesis in the Adult Hippocampus. Cold Spring Harb Perspect Biol 7: a018812. [Crossref]

53. Cotman CW, Nieto-Sampedro M (1984) Cell biology of synaptic plasticity. Science 225: 1287-1294. [Crossref]

54. Chang FL, Greenough WT (1984) Transient and enduring morphological correlates of synaptic activity and efficacy change in the rat hippocampal slice. Brain Res 309: 35-46. [Crossref]

55. Ashford JW (2002) ApoE4: is it the absence of good or the presence of bad? $J$ Alzheimers Dis 4: 141-143. [Crossref]

56. Ashford JW (2015) Treatment of Alzheimer's Disease: The Legacy of the Cholinergic Hypothesis, Neuroplasticity, and Future Directions. J Alzheimers Dis 47: 149-156. [Crossref]

57. Ashford JW (2017) Plasticity in Alzheimer's Disease. Presented on April 20, 2017 in the Session Neuroplasticity in Medical Illnesses and Psychiatric Syndromes, 14th Annual World Congress of the Society for Brain Mapping and Therapeutics, Los Angeles CA.

58. Weissman L, de Souza-Pinto NC, Stevnsner T, Bohr VA (2007) DNA repair mitochondria, and neurodegeneration. Neuroscience 145: 1318-1329. [Crossref]

59. Jackson SP, Bartek J (2009) The DNA-damage response in human biology and disease Nature 461: 1071-1078. [Crossref]

60. Rass U, Ahel I, West SC (2007) Defective DNA repair and neurodegenerative disease. Cell 130: 991-1004. [Crossref]

61. Ljungman M, Lane DP (2004) Transcription - guarding the genome by sensing DNA damage. Nat Rev Cancer 4: 727-737. [Crossref]

62. Wang X and Michaelis EK (2010) Selective neuronal vulnerability to oxidative stress in the brain. Front. Aging Neurosci 2: 12. [Crossref]

63. Sacher GA (1977) Life table modification and life prolongation, in The Handbook of the Biology of Aging, Finch CE, and Hayflick L, eds., Van Nostrand Reinhold, New York 582-638.

64. Strehler BL (1977) Time, Cells, and Aging, Academic Press, New York.

65. Hirsch HR (1995) Do intersections of mortality-rate and survival functions have significance? Exp Gerontol 30: 147-167. [Crossref]

66. Alzheimer's Association (2017). What is Alzheimer's? [Crossref]

67. Hacker JD (2010) Decennial Life Tables for the White Population of the United States, 1790-1900. Hist Methods 43: 45-79. [Crossref]

68. National Eye Institute. Cataracts (2010) US age-specific prevalence rates for cataract by age, and race/ethnicity. [Crossref]

69. The Eye Diseases Prevalence Research Group (2004) Prevalence of Age-Related Macular Degeneration in the United States. Archives of Ophthalmology 122: 564-572. [Crossref]

70. Fullerton SM, Clark AG, Weis KM, Nickerson DA, Taylor SL, et al. (2000) Apolipoprotein $\mathrm{E}$ variation at the sequence haplotype level: implications for the origin and maintenance of a major human polymorphism. Am. J. Hum. Genet 67: 881-900. [Crossref]

71. Farrer LA, Cupples LA, Haines JL, Hyman B, Kukull WA, et al. (1997) Effects of age, sex, and ethnicity on the association between apolipoprotein $\mathrm{E}$ genotype and Alzheimer disease: A meta-analysis. JAMA 278: 1349-1356. [Crossref]

Copyright: (C2017 Smith CJ. This is an open-access article distributed under the terms of the Creative Commons Attribution License, which permits unrestricted use, distribution, and reproduction in any medium, provided the original author and source are credited. 